
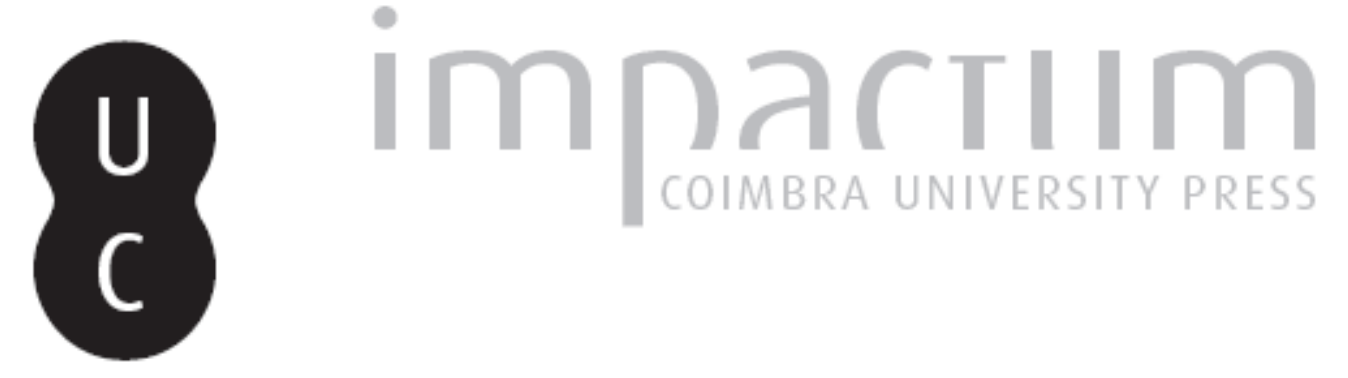

\title{
O que significa ouvir? A "audiência" como constituinte da Filosofia da Música enquanto Filosofia pura
}

Autor(es): $\quad$ Carvalho, Mário Santiago de

Publicado por: Imprensa da Universidade de Coimbra

URL persistente:

URI:http://hdl.handle.net/10316.2/35512

DOI:

DOI:http://dx.doi.org/10.14195/0870-4112_11_14

Accessed : $\quad$ 26-Apr-2023 11:07:15

A navegação consulta e descarregamento dos títulos inseridos nas Bibliotecas Digitais UC Digitalis, UC Pombalina e UC Impactum, pressupõem a aceitação plena e sem reservas dos Termos e Condições de Uso destas Bibliotecas Digitais, disponíveis em https://digitalis.uc.pt/pt-pt/termos.

Conforme exposto nos referidos Termos e Condições de Uso, o descarregamento de títulos de acesso restrito requer uma licença válida de autorização devendo o utilizador aceder ao(s) documento(s) a partir de um endereço de IP da instituição detentora da supramencionada licença.

Ao utilizador é apenas permitido o descarregamento para uso pessoal, pelo que o emprego do(s) título(s) descarregado(s) para outro fim, designadamente comercial, carece de autorização do respetivo autor ou editor da obra.

Na medida em que todas as obras da UC Digitalis se encontram protegidas pelo Código do Direito de Autor e Direitos Conexos e demais legislação aplicável, toda a cópia, parcial ou total, deste documento, nos casos em que é legalmente admitida, deverá conter ou fazer-se acompanhar por este aviso.

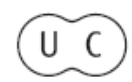




\section{ESTÉTICA E POLÍTICA}

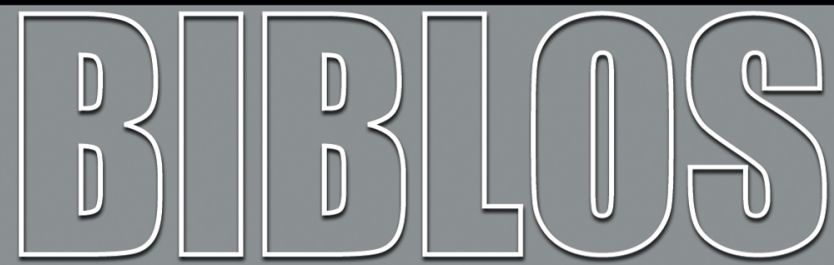

REVISTA DA FACULDADE DE LETRAS UNIVERSIDADE DE COIMBRA 
Biblos, n. s. XI (2013) 341-356

DOI: http://dx.doi.org/10.14195/0870-4112_11_14

Mário Santiago de Carvalho

Departamento de Filosofia, Comunicação e Informação da FLUC

\title{
O QUE SIGNIFICA OUVIR? \\ A "AUDIÊNCIA" COMO CONSTITUINTE DA FILOSOFIA DA MÚSICA ENQUANTO FILOSOFIA PURA
}

\section{Resumo}

Sustentamos, em primeiro lugar, que a filosofia da música tem a sua moderna constituição em dois momentos distintos mas próximos no tempo, a fundação da etnomusicologia e da estética modernista na esteira de L. Russolo; de seguida, determinamos que a filosofia da música tem no tema da escuta a que chamamos, num neologismo, "audiência" - a possível charneira para a passagem da filosofia da música de uma filosofia aplicada a uma filosofia "pura"; concluímos a artigo pensando precisamente o tema da "audiência".

Palavras-chave: Filosofia, filosofia da música, "audiência”, estética/poiética, som, ruído.

\begin{abstract}
Firstly, it is argued that philosophy of music has its modern constitution with two distinct but close moments in time, the foundation of ethnomusicology and of the modernist aesthetics following L. Russolo; secondly, it is determined that listening - or in a neologism, "audience" (as a parallel to "evidence') - has a pivotal role in philosophy of music enabling its transition from an applied philosophy to "pure" philosophy; lastly, the article sets forward the theme of "audience".
\end{abstract}

Keywords: Philosophy, Philosophy of Music, "audience", aesthetics/ poietics, sound, noise. 
0. Gostaríamos de alinhavar dois considerandos provisórios, quiçá intempestivos, em torno da constituição da denominada "filosofia da música”. A designação é recente, poderá datar de 1870, precisamente da pena de Wagner, num ensaio deste sobre Beethoven. Retomada no século seguinte por Adorno, também a propósito de Beethoven ${ }^{1}$, apesar de se poder ler já em E. Hanslick (1854) algo assim como a "fundamentação filosófica da música" (philosophische Begründung der Musik) ${ }^{2}$, a expressão "filosofia da música" remete, pela sua própria natureza de fronteira, para uma dissensão epistémico-metodológica. Referimo-nos à possibilidade do seu desenvolvimento por banda de um praticante $\mathrm{e}$ especialista da música ou pelo lado de quem se dedica à filosofia, ambos os flancos acusando-se mutuamente de mais ou menos ignorância, para dizer o mínimo. Esta inevitável situação, obrigando-nos à assunção do dissídio como lugar donde, pode e deve ser praticada num constante vaivém disciplinar que colha a lição, de novo de Adorno (leia-se a pretensão da Philosophie der neuen Musik de 1948), segundo a qual uma filosofia da música só faz sentido no horizonte da contemporaneidade ${ }^{3}$, e que assuma, depois, agora pela nossa parte, mas em consonância com a lição acabada de lembrar, a permanente disponibilidade para novas e inesgotáveis composições (sendo esta a palavra certa, em se tratando de música).

Diversamente do procedimento habitual, preconizamos, também em alternativa ou como superação do dissídio que lembrámos, que o convívio com a filosofia da música não tem de se restringir a uma filosofia aplicada, mas pode ser um excelente pretexto para nos abalançarmos adentro de uma filosofia pura. "Pura", entenda-se, uma vez que falamos de música, não na aceção com que tradicionalmente se lê o arco filosófico ou estético-formalístico de Hanslick a P. Kivy; recordemos que aí

${ }^{1}$ G ZÖLLER, “A música como vontade e representação" Cadernos de Filosofia Alemã 16 (2010), 56, nota 4; R. WAGNER, Sämtliche Schriften und Dichtungen: Volume IX (1870), pp 61-126 [trad. ingl. de W. A. Ellis agora in: http://users.belgacom.net/wagnerlibrary/prose/wlpr0133.htm - consultado em novembro de 2013]; Th. W. Adorno, Beethoven: The Philosophy of Music, transl., Stanford 1998.

${ }^{2}$ Cf. E. Hanslick, Do Belo Musical. Um contributo para a revisão da Estética da Arte dos Sons. Trad. de A. Morão, Lisboa 2002, p. 47.

${ }^{3}$ Th. W. Adorno, Philosophy of Modern Music, transl., London 1973; p. 10, que traduzimos: "A filosofia da música hoje só é possível como filosofia da música moderna". 
"pura" opõe-se v.g. a "programa", pensando-se imediatamente, a título de exemplo, em peças como o Concerto para 2 violinos em Ré menor BWV 1043 de J.S. Bach, ou o Quarteto n. ${ }^{\circ}$ 15, Opus 132 de Beethoven, ou ainda, de Alban Berg, o Concerto de 1935 para violino. "Pura", outrossim, no sentido em que, a assunção corajosa do facto da música ser sempre uma ideia, embora uma ideia tão complexa já, isto é dizer, histórica sempre, tornar possível e legítima a ultrapassagem de uma abordagem filosófica aplicada ou de segundo nível - isto não só pelo recurso a um "corpo de pensamento básico sobre a natureza da música" como também a uma analítica das formas que legitimem racionalmente a própria possibilidade da música ${ }^{4}$. Semelhante ambição teórica e programática poderá ocorrer, e esta é apenas uma hipótese, sob o prisma da temática ou da problemática da escuta ou da audição - o que significa ouvir? Para o efeito recorreremos ao vocábulo "audiência", na aceção em que se entende, pelo menos para já, qualquer ação de ouvir ou de dar atenção a alguém ou a alguma coisa sonora. "Audiência" será aqui, no campo específico de uma filosofia da música, e com todas as reservas possíveis e necessárias - nomeadamente a sua implicação com as metáforas do ouvido ${ }^{5}$, o paralelo ou o correspondente a "evidência", este um vocábulo, do qual o autor com quem acabaremos por dialogar no fim destas breves considerações, Fernando Gil, disse, e com razão, que "trabalha todo o pensamento da verdade"

${ }^{4}$ L. Rowell, Introducción a la filosofia de la música. Antecedentes históricos y problemas estéticos, trad., Barcelona 1983, p. 236: "A ideia de música (e a música é uma 'ideia' na exata medida em que o é qualquer outra coisa) já não é uma ideia simples (...) mas um conjunto de ideias alternativas, cada uma apoiada pelos seus próprios pressupostos, profetas, escrituras e valores. Pensar o próprio caminho através da confusão de palavras e de ideologias conflituantes exige mais que a guia da crítica competente (filosofia 'aplicada'); exige a ajuda de um corpo de pensamento básico sobre a natureza da música (filosofia "pura')."

${ }^{5}$ Cf. F. GiL, Tratado da Evidência, trad., Lisboa 1996, p. 21. Sobre esta obra, vd. o nosso «'Tremendos são os deuses quando aparecem às claras'. Notas sobre a Evidência, 'in memoriam Ferdinandi Gil'», in AA.VV., A Razão Apaixonada. Homenagem a Fernando Gil, Lisboa 2008, pp. 129-142. Embora numa direção diferente da nossa, pensar a "auris" é também o desafio de R. Grácio, "A que soa um mundo feito de sons?", in J. Braga e C. Carvalho (eds.), Leituras da Sociedade Moderna. Média, política, sentido, Coimbra 2013, pp. 49-66.

${ }^{6}$ F. GiL, Tratado..., p. 9. 
Consequentemente, ainda antes de abrirmos uma reflexão possível sobre a "audiência" ( $(2)$, avançaremos com a nossa hipótese explicativa sobre a constituição da filosofia da música $(\S 1)$.

1. A coisa é óbvia, como por exemplo para qualquer leitor de Platão": se a denominação "filosofia da música" é recente, a matéria parece não sê-lo. A crermos em P. Alperson ${ }^{8}$, os Gregos teriam sido responsáveis pelas quatro seguintes áreas integradoras de um profícuo pensamento sobre a música: (i) o formalismo, isto é, a preocupação com as qualidades da forma musical, (ii) o expressionismo, isto é, o interesse pela expressão, por exemplo, no âmbito da conexão música e emoção; (iii) o metafisicismo, quer dizer, a preocupação com as origens e o significado ontológico, cosmológico ou religioso da música; (iv) o eticismo, ou a atenção aos efeitos e ao papel da música na construção e manutenção de uma sociedade mais ou menos ideal. Ora, mesmo concordando com um tal reconhecimento, o século XIX, mas sobretudo o século XX, assistiram a uma deflagração - chamemos-lhe epistemológica - a qual, no campo da música, se deixa condicionar e determinar, a nosso ver, por duas situações independentes. Elas rompem precisamente com a proposta quadripartida de Alperson. A primeira, na passagem do século, está ligada à rutura com a longa preponderância cultural europeia do modalismo e do tonalismo ditos clássicos, rutura assinalável pelo aparecimento ou desenvolvimento da etnomusicologia; além da rutura com uma certa ideia de música, a primeira consequência desta situação cruzará uma expansão com um aprofundamento. A segunda deflagração, quiçá datável de 1913, diz respeito ao abalo produzido na preponderância da problemática do Belo e a consequente instauração do Poiético, isto é, da consideração da ação ou da produção, musical no caso. Consideremos cada uma delas, ainda que brevemente.

Definida pelo professor austríaco Guido Adler $(1885)^{9}$ como o ramo da musicologia sistemática (systematische Musikwissenschaft)

${ }^{7}$ Cf. E. Moutsopoulos, La musique dans l'oeuvre de Platon, Paris 1989.

${ }^{8}$ P. Alperson, "Music as Philosophy", in Id. (ed.), What is Music? An Introduction to the Philosophy of Music, Pennsylvania 1987, p. 5.

${ }^{9}$ Guido Adler, "Umfang, Methode und Ziel der Musikwissenschaft" Vierteljahresschrift für Musikwissenschaft, 1, 5-20; apud Erica Mugglestone, "Guido Adler's 'The Scope, Method, and Aim of Musicology' (1885): An English Trans- 
que teria como tarefa a comparação das obras musicais, especialmente as canções folclóricas dos vários povos da terra, para propósitos etnográficos, e a classificação delas de acordo com suas várias formas, a etnomusicologia, antropologia da música ou etnografia da música, surgiu primeiro com o nome de musicologia comparada (Musikologie ou Vergleichende Musikwissenschaft); a mudança do nome é normalmente atribuída a Jaap Kunst, no seu livro de 1950, Musicologia ${ }^{10}$. Trivial opinião da qual também nós partilhamos: o surgimento da etnomusicologia só foi possível graças à invenção do fonógrafo, em 1877 por Thomas Edison. Quase um século depois, o caso português em particular é disto mesmo representativo, quando Michel Giacometti e Fernando Lopes-Graça editam a Antologia da Música Regional Portuguesa (196070) ${ }^{11}$, o primeiro armado precisamente de um instrumento de gravação, isto é, de uma memorialização que habilite a uma escuta (e não só a uma leitura) primeiro analítica, depois interrogante, exigente e cada vez mais abarcante. Giacometti repetia ou aclimatava a intervenção do mais conhecido etnomusicólogo, o pianista e compositor húngaro Béla Bartók. Esta história é conhecida: percorrendo a Hungria e a Roménia, e conjuntamente com o não menos célebre Z. Kodaly, o metódico registo sonoro constituinte da possibilidade da comparação e da classificação de músicas até então esquecidas ou desprezadas pela "cultura superior" não se enquadra adequadamente em nenhuma das quatro modalidades evocadas. A aproximação será doravante epistémica e assenta na expansão ou no alargamento da ideia (do mundo) da música. Tocando doravante em franjas da sociedade até então desprezadas uma outra geografia da música estará prestes a criar as condições para a invenção do que hoje chamamos presunçosamente as "músicas do mundo"12. Uma pergunta impõe-se, portanto, naturalmente: e se a música tiver os contornos do próprio mundo, ou for a sua própria medida? E porque desta pergunta um equívoco imediato pode advir, qual o de a circunscrever

lation with an Historico-Analytical Commentary," Yearbook for Traditional Music vol. 13 (1981), pp. 1-21.

${ }^{10}$ Cf. Georg List, "Ethnomusicology: a Discipline defined", Ethnomusicology 23, n. 1 (jan. 1979), p. 1.

${ }^{11}$ Agora in: http://portugalsom.wordpress.com/musicaregional/ (consultado em dezembro de 2013).

${ }^{12}$ Cf. José E. Braga, Música do Mundo, Coimbra 2009. 
ao espaço da antropologia, uma segunda surge inevitavelmente: E se acaso acontecer que só uma disfarçada glosa do velho Protágoras - a música é a medida de todas as coisas - for suscetível de fundar autenticamente e instaurar na sua profundidade própria uma exigente filosofia da música? Chegaríamos, por isso, a dizer que "não há conhecimento da música sem filosofia. Não, na medida em que esta 'explica' ou 'verbaliza' aquela, mas sim na medida em que precisamente o não faz, isto é: na medida em que nos coloca naquela perspetiva de audição ou perceção em que a dimensão cognitiva tem um modo não verbal ou não discursivo de se manifestar." 13

Se as chamadas músicas do mundo ainda podem ser ouvidas sob o prisma da beleza, embora agora mais aberta, rasgada e desafiadora no seu espaço cada vez mais global, o segundo elemento constituinte que queremos evocar é conhecido por ter querido colidir frontalmente com a estética tradicional, vigente e imperante. Referimo-nos à fundação, pelo futurista italiano Luigi Russolo, do "ruidismo" (de "ruídos sonoros"), o mais radical movimento da modernidade estética. Não sendo os futuristas músicos, mas sobretudo pintores ou escritores interessados pela música, o seu interesse explicitamente programático visava a rutura com a música do passado, tal como, evidentemente, a entendiam, ou seja, mediante a abolição dos instrumentos tradicionais e convencionais, o alargamento dos sons... até ao infinito, a expansão do campo da sonoridade, a própria possibilidade enfim de se acabar com a diferença, dir-se-ia inamovível (mas apesar de tudo sempre cultural), entre som e ruído. Uma obra como Risveglio di una Città (1913), mas não menos Macchina Tipografica, são disso pungentes testemunhos e dificilmente poderíamos obliterar a sua importância e influência na música eletrónica do século XX, do uso dos sintetizadores à música concreta. Eis-nos perante uma revolução com efeitos inesperados. $\mathrm{O}$ moderno ouvinte habilita-se, por um lado, ao desafio de um alargamento da escuta, a um processo audiente virtualmente tão global quanto o do direito ao reconhecimento como música e, por outro, a ser o próprio criador de uma estrutura sonora a que com toda a legalidade pode chamar "música". Esta é a história meramente ocidental que ligaria Pierre Schaeffer

${ }^{13}$ M.V. de Carvalho, "Apresentação”, in F. Gil \& Mário Vieira de Carvalho, A 4 mãos. Schumann, Eichendorff e outras notas, Lisboa 2005, p. 7 
(Etudes aux chemins de fer, 1948) ao Poema sinfónico para 100 metrónomos (1962) de G. S. Ligeti, permitindo também que nela se incluam obras de registo pop como Florentine Pogen (de F. Zappa), Autobahn (1974), dos Kraftwerk, e Atom heart mother (1969), dos P. Floyd, conquanto que também, num género distinto embora, The Desert Music (1982/3) de S. Reich ou Telemusik (1966) de K. Stockhausen.

Em suma, a criação da musicologia no século XIX (e depois da etnomusicologia), por um lado, e a necessidade crescente de se afinar ou confrontar cada vez mais as fronteiras entre o som musical e o som não-musical - dito mais prosaicamente: o som e o ruído - prepararam o terreno para uma refundação da filosofia da música no século $\mathrm{XX}$, diríamos ainda mais: para a sua verdadeira constituição. A episteme da música passa a poder visar assim os contornos do mundo todo, com o consequente desafio (utópico?) de uma escuta total de tudo o que há para ouvir.

Insistamos um pouco mais. A libertação do estudo da música do mero contexto das belas artes (situação para a qual ela se remetera em meados do século XVIII), e sobretudo do quadro da filosofia da arte que possibilitou a autonomização que perseguimos pode ter a direção precisa da passagem da estética da música à poiética da mesma ${ }^{14}$. De uma maneira singular o século $\mathrm{XX}$ assistiu à perda de prestígio pela indagação do Belo, no sentido do "que é representado sem conceitos como objeto de um comprazimento universal" (KUr § 6) ${ }^{15}$, substituído pelos intentos analíticos relativos à produção da música, ao seu Fazer. Visando-se a justificação e a explicação exaustivas deste processo requisitava-se não só o reconhecimento e a compreensão do modo como a música é feita, quanto, ao mesmo tempo, a interrogação sobre os limites - dir-se-iam ilimitados, pleonasmos à parte - do fazer-música. E é aqui que irrompe a outra dissidência a que já aludimos, som/ruído, agora tornada matéria legitimamente pensável. Pondo em causa uma respeitável tradição, Dahlhaus reconhecia que "só a música eletrónica e a "composição de sons' inspirada por John Cage suscitaram o problema de se fenómenos sonoros que negam o sistema tonal serão ainda música, no sentido da

${ }^{14}$ Cf. C. Dahlhaus \& H. EgGebrecht, Que é a música?, trad., Lisboa 1985, p. 127 .

${ }^{15}$ I. Kant, Crítica da Faculdade do Juízo. Introd. de A. Marques. Trad. e notas de A. Marques \& V. Rohden, Lisboa 1992, p. 99. 
tradição europeia" ${ }^{16}$. Recordemos, pela nossa parte, e como sintoma bem sonoro do que acabámos de dizer (haja em vista o poder vital ou original da percussão), a entrada desta como instrumento prioritário na música, o que só acontece no século XX de novo com Cage, mas sobretudo com Lou Harrison, tal como se escuta no célebre Concerto para violino e gamelão deste último. Ora, qualquer pessoa reconhece, primeiro, não ser a mesma coisa a utilização de apitos ou bigornas em peças musicais (foi o que sucedeu de Lully a Wagner ou Verdi), isto é, a intromissão crescente do "ruído" no campo da sonoridade e, depois, a teorização do silêncio não já só na música, mas fora da música. Notemos bem esta última situação: acompanhando J.-J. Nattiez, quer a respeito da impossibilidade do silêncio absoluto como condição da música, quer no tocante àqueles dois tipos de silêncio e às suas duas subespécies no seio da música ${ }^{17}$, permitimo-nos sublinhar não ser a mesma coisa, nesta última subconsideração: (i) falar-se da utilização expectante que Beethoven fez do silêncio - o exemplo recordado é a pausa que se segue à exposição do primeiro tema na terceira sonata para piano do compositor romântico -, (ii) falar-se do valor em si do silêncio, como, por exemplo, para fazer valer a expressão de uma frase, tal os casos de Mahler ou de Debussy, e por fim ainda (iii) falar-se da aventura do silêncio como obra musical em si. Quanto a esta última subespécie, de facto a mais relevante na presente consideração, e aliás só possível, também, pela abolição das cadências tonais, qualquer pessoa evoca as composições de Ligeti ou o célebre 3'44" de J.Cage. Numa palavra, a amplificação da sonoridade musical, a introdução de sons, ruídos, hábitos urbanos, mas não menos a introdução não-arbitrária, ou melhor ainda, do silêncio enquanto obra que (se) escuta tornariam inevitável a imposição de uma nova atitude auditiva, audiente; e por isto mesmo: a constituição da escuta como problema filosófico (não religioso), haja em vista a aventura subjacente à sempre necessária análise ou discriminação do espaço indefinidamente crescente do especificamente musical.

2. Tendo acabado de descrever duas condições para uma filosofia da música mais moderna, estamos em condições de pensar de frente

${ }^{16}$ Cf. C. Dahlhaus \& H. EgGebrecht, Que é a música?, p. 16)

17 J.-J. NAtTiEz, "Som/ruído", in Enciclopédia Einaudi 3. Artes-Tonal/Atonal, trad., Lisboa 1984, p. 213. 
a escuta, de Pitágoras a Fernando Gil v.g., a fim de introduzirmos, tal como enunciámos no preâmbulo, a temática da "audiência" enquanto constituinte de uma filosofia pura no próprio seio da prática da filosofia da música. A evocação do filósofo português justifica-se naturalmente não só por ter sido ele, na nossa área, tanto quanto sabemos, a levar mais longe (e de modo breve, admiravelmente) o pensamento da música, quanto pelo pretexto de reatarmos um também breve diálogo com ele iniciado há alguns anos.

O deslocamento da fronteira da música entrando nos domínios do ruído foi operado por Russolo, Schaeffer, Cage ou Murray Schafer. Cage disse-o na perfeição, aludindo à nova escuta: "mais se descobre que os ruídos do mundo exterior são musicais, e mais música existe"18. É já um lugar comum dizer-se que o célebre acorde de Tristão e Isolda - em 6/8 os violoncelos num salto de sexta lá-fá, a dissonância fá-si-ré sustenido-sol sustenido, depois um acorde menos dissonante sem que qualquer terceiro acorde venha resolver a dissonância - foi ouvido pela primeira vez, segundo os hábitos harmónicos da época, como se de ruído se tratasse, mas o ponto está em que, distintamente de Wagner, para quem o cromatismo era chamado a exprimir o desejo amoroso numa ótica bramânica ${ }^{19}$, todos os restantes compositores acabados de citar pretenderam outra coisa. Temos de o repetir: tratava-se sim de chocar o auditório, mas isso fundava-se num apelo para revolucionar a linguagem musical, isto é dizer, para alargar o território do especificamente musical.

À parte o inevitável pendor vanguardista, este sempre mais estético e social, o alargamento do território da sonoridade musical representa para nós, aqui, que visamos a eclosão de uma "filosofia pura", isto é, não aplicada, algo mais do que a mera ideia segundo a qual, e interpretando de novo termos de Adorno, o que concita hoje verdadeiro interesse filosófico é a não-conceptualidade, a individualidade, a particularidade, tudo aquilo, enfim, que a filosofia de Platão desconsiderou ${ }^{20}$. Apontaremos justamente o contrário, embora afastando-nos da mera consideração estética: só o alargamento do território da sonoridade

${ }^{18}$ J. CAge, Pour les oiseaux. Entretiens avec Daniel Charles, Paris, 1976, p. 68 ; apud J.-J. Nattiez, "Som/ruído », p. 222.

19 J.-J. NAtTiez, "Som/ruído", p 216.

${ }^{20}$ Cf. Alex Thomson, Compreender Adorno, trad., Petrópolis 2010, p. 64. 
musical - silêncio incluído - tornou legitimo o tom central de uma, entretanto autonomizada, filosofia da música, posta assim em condições de devir filosofia pura.

Uma vez que nossa perspetiva não é histórica nem estética, tendo por isso de começar por opor à novidade a atualidade (na aceção aristotélica da energeia), convirá acrescentar os dois pontos seguintes; eles ilustrarão a contrario o terreno que não pretenderemos pisar aqui. Pensando decerto em peças atonais pioneiras como, e antes de todas mais, o segundo quarteto para cordas Opus 1 , logo seguido do ciclo Das Buch der Hängenden Gärten, Op. 15 (1908-1909), as suas Cinco Peças para Orquestra, Opus 16 (1909), o perturbante Pierrot Lunaire, Op. 21 (1912) ou o dramático Erwartung, Op. 17 (1909), em A Filosofia da Música Moderna Adorno apressara-se a prescrever o que deveria ser a arte contemporânea, enfatizando a inovação de Schoenberg, o compositor de todas as peças acabadas de mencionar. Na leitura de Adorno a novidade não consistira tanto na rejeição da tradição quanto na sua ampliação, ou na exploração de uma possibilidade inerente à música ocidental que por convenções formais nunca tinha podido vir ao de cima. Ao invés de Stravinsky, o sucesso de Schoenberg estaria no choque que a receção da sua obra produziu, o choque do novo que caracteriza a arte autónoma. "Conteúdo de verdade" e "música não padronizada" impuseram-se assim como temas fecundos na vertente aplicada da filosofia da música. Este é, como se compreende, um caso mais daqueles em que a filosofia é utilizada na música como segundo nível, como aplicação, aliás "sociológica" à boa maneira de Frankfurt, apesar da permissível ligação de toda esta problemática ao tema da escuta, num sentido mais débil embora. Com efeito, abolindo a era de Rameau e dos seus princípios naturais, como salvo erro dizia Boulez, a omnipresença da série ou o facto de o tema da música dodecafónica ser o seu próprio processo de construção fez com que o sujeito fosse levado à necessidade de ouvir a estrutura e o plano construtivo, sendo este o sentido fundamental da audição estrutural segundo Schoenberg.

Segundo ponto prévio relativo à nossa pretensão de substituição da novidade pela atualidade como condição de se pensar a escuta audiente - a "audiência". Também não propenderíamos para a linguagem das revoluções enquanto leitura da música moderna. Analisando tecnicamente peças de Brahms, Schönberg, Webern e Stockhausen, a partir da célebre obra de 1962 de Thomas Kuhn, A Estrutura das Revoluções 
Científicas, Antonio Lai deteve-se na génese, na evolução e na crise da linguagem tonal e da linguagem serial, insistindo no caráter cumulativo das soluções tonais, e no aparecimento da rutura da linguagem serial como verdadeira revolução musical ${ }^{21}$. Estudando a evolução da harmonia, sob o tópico da tónica, dominante e subdominante, Lai também via na preponderância da função dinâmica da dominante nas harmonias revolucionárias de Wagner autênticos sintomas da crise da tonalidade (aludimos acima ao célebre acorde de Tristão e Isolda). Ler a tentativa de resposta de Schönberg mediante uma refundação radical da linguagem musical - a linguagem serial tornou-se hegemónica após a crise da tonalidade, pelo menos até aos polémicos anúncios da chamada "nova tonalidade" 22 -, na sequência da descoberta wagneriana das incongruências do sistema tonal também equivale a deixar de lado o que importa, a nosso ver, pensar. De facto, os exemplos concitados de Adorno e de Lai, provenientes de campos diversos, servem-nos aqui para evidenciar tão-só, mas a contrario, lembramos, como sob o prisma da "audiência" urge impor outra dimensão ou plano. De nada serviria, por isso, acrescentar-se ainda alguma tendência main streem no contexto musical anglosaxão (Steve Reich, John Adams, Terry Riley, Phillip Glass, Thomas Adès, Howard Skeptom, entre outros) ou eslavo (Arvo Pärt, Schnittke, Penderecki), que busca a "nova tonalidade" após a emancipação da dissonância, como ocasião para pensarmos o que deve ser pensado. Aludiremos tão-só a um caso limite: pelo seu cunho paródico, peças de um dos mais considerados compositores norte-americanos, John Adams, como Grand pianolla music (1982) ou o segundo movimento de Century Rolls (1996) - uma paródia das Gymnopédies, entre arranjos de piano-bar e modulações de Satie - articulando, colando ou

${ }^{21}$ Antonio LaI, Genèse et révolutions des langages musicaux, Paris Budapest Torino 2002. Não teremos, obviamente, de referir aqui todas as perspetivas cujos métodos não compartilhamos, mas não podemos deixar de evocar, ao menos pelo seu poder de atração, a que decorre dos avanços do conhecido "Hudrum Toolkit", explorado por David Huron (1989 em diante), como por exemplo no âmbito da memória memética, como em Steven Jan, The Memetics Of Music. A Neo-Darwinian View of Musical Structure and Culture, Aldershot Burlington, 2007; num horizonte afim, mas num âmbito completamente diferente veja-se também F. LEón

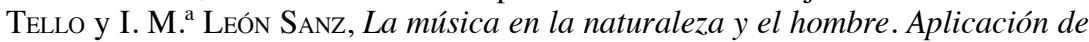
la teoria de Darwin a la musicologia, Madrid 2012.

${ }^{22}$ Cf. R. Scruton, The Aesthetics of Music, Oxford 2009, p. 508. 
mesmo justapondo o caos - explicitamente: o "lixo" - como atitude vanguardista da chamada nova tonalidade numa estratégia de disponibilização integral do material e do livre uso de formas não passa de uma posição estética regressiva, que nos manteria aprisionados a uma prática da filosofia aplicada.

Passaremos então a postular o que não podemos provar. Comecemos por propor a dimensão excessiva da música. Não só porque o seu componente, o som, agora alargado, "excede o sentido" 23 - e, por isso, mesmo sem dizer "o ser, nem diretamente nem por um simulacro de ontologia negativa" ${ }^{24}$, requisita soberanamente uma meta-ontologia -, mas sobretudo porque na sua radicalidade é já, desde sempre, o imperscrutável som originário. Um big bang mundano (na aceção pitagórica e sobretudo boeciana deste adjetivo), isto é, sonoro e ruidoso, que concita sempre e inevitavelmente o ato da escuta, auroralmente anterior a qualquer outro ato. Ora, o ato da escuta - o que significa 'ouvir' - não poderá ser menos excessivo, em qualquer caso cada vez mais amplo (como a amplitude sonora estudada na acústica), na exata medida em que a música - e será o nosso segundo postulado - é soberana, quer dizer, virtualmente totalizadora; será aliás por essa razão, ou seja, porque ocupa todo o espaço à sua disposição, que a música é um fator de comunidade ${ }^{25}$, tal como já o sublinhámos com Alperson, e originalmente a respeito de Platão, embora ultrapassada agora como diremos a seguir com E. Bloch ${ }^{26}$. Excessiva e soberana ela é depois autossuficiente, autónoma, quer dizer um mundo próprio. Como escreveu com absoluta acribia Fernando Gil, a "autossuficiência da música advém-lhe da realidade do som, e de o som musical ocupar todo o campo da aten-

${ }^{23}$ F. Gil, "Exemplos Musicais ", in F. Gil \& Mário Vieira de Carvalho, A 4 mãos. Schumann, Eichendorffe outras notas, Lisboa 2005, p. 30.

${ }^{24}$ F. GIL, "Exemplos...", p. 23; para uma aplicação débil de "ontologia”, vd. R. Pouivet, Philosophie du Rock. Une ontologie des artefacts et des enregistrements, Paris 2010.

${ }^{25}$ Cf. F GIL, "Exemplos...”, p. 30.

${ }^{26}$ Veja-se também N. Carroll y Ph. Alperson, "Música, mente y moralidad: moviendo el cuerpo político", in M. a José Alcaraz y F. Pérez CArreño (eds.), Significado, emoción y valor. Ensayos sobre la filosofía de la música, Madrid 2010, pp. 261-286. 
ção, sem mais nada, sem que nenhuma significação se junte à escuta e sem que a escuta sofra por isso" 27 .

Pondo de parte a sua dimensão comunitária da música, a qual não passa da apesar de tudo complexa expressão antropológica e sócio-política inerente ao seu radical estatuto mundano, gostaríamos de apenas começar por pensar o modo como na triangulação excesso/soberania/autossuficiência se pode introduzir a temática ou a problemática da "audiência". Concitando no mesmo passo Santo Agostinho e Ernst Bloch, foi ainda F. Gil quem nos chamou a atenção para o facto de a escuta ser não apenas, não especialmente, individual, mas sobretudo pessoal. Na medida em que a música "é também um fator de interioridade... Imperiosa, apodera-se da escuta, que se lhe submete, pois a música ecoa nos sentimentos originários. Não pode não agir sobre eles, que não lhe podem fugir pois é o veículo expressivo que naturalmente se lhes adequa. A música efetua naturalmente e sem esforço o 'reddi in te ipsum' de Agostinho. Regressar a si próprio requer uma decisão, a consciência vive distraída e imersa no mundo sensorial que em permanência a solicita, e do qual os ruídos fazem parte. É esse mundo exterior que a música anula ipso facto - como ressalta da perceção inesperada de um som musical que nos obriga a parar e a prestar atenção em nome próprio, condição inicial do movimento de interiorização. A escuta não é simplesmente individual, é pessoal. Indo mais longe, Ernst Bloch coloca como pedras basilares da sua conceção da música as proposições não demonstráveis (1) que 'não nos ouvimos senão a nós', wir hören nur uns - a escuta é escuta de si próprio -, e (2) que a música é por essência comunitária, utopia antecipada." ${ }^{28}$.

Apesar de algo longa a citação impunha-se. Vejamos porquê. O império da música, a outra forma de enunciar as três dimensões que referimos supra, impõe-se, a nosso ver, mas não só como atenção em nome próprio. Diremos até mais: o seu império só se perfaz quando se radicaliza a escuta "em nome próprio" pela assunção da escuta do nome próprio, a outra maneira de enunciarmos a totalidade que se impõe à escuta digna do seu ato. Questão de concentração, não de dispersão,

${ }^{27}$ F. GIL, "Exemplos...”, p. 22.

${ }^{28}$ Gil, "Exemplos...”, p. 30-31 (os itálicos são do autor); cf. MANUEl Ferreira PAtrício, "Evocação de Fernando Gil no espírito da música", in AA.VV., A Razão Apaixonada. Homenagem a Fernando Gil, Lisboa 2008, pp. 7-17. 
ou melhor ainda, de não distração. Comprometido como um todo na escuta da exuberância ou do excesso, da soberania ou da exclusividade, da autossuficiência ou mundo próprio que só a música parece ser, o Homem que ouve, o Homem audiente não é - não pode continuar a ser - o analista musical, consciente de que este processo de explicação e de linguagem fica aquém do que nunca foi ouvido, do que ainda há para ouvir, o inaudito, portanto. Há aqui muito de disciplina escutante, como é natural, e sempre saliento aos meus alunos, antecipando-lhes a inevitável recriação do eu daí decorrente - "é também pela continuidade de uma experiência perdurante que a identidade se constrói" ${ }^{29}-$, desde logo porque "a música só existe através do eco perdurante, no ouvido e na mente, na mente como ouvido, da música que se ouviu imediatamente antes; só assim se está a ouvir, durante um intervalo de tempo."30 Mas deve haver ainda algo mais do que a disciplina, algo como a disponibilidade e a abertura que permitem o trânsito da pessoalidade da homofonia à escuta da (sua) heterofonia; o outro (no) som.

Chamemos-lhe também vulnerabilidade, esta em nada incompatível com o arrojo, com a coragem implicada, a vigilância mesmo - e como não podiam ser estas as palavras adequadas ao "excesso" de que temos vindo a falar? - daquele que escuta devir ipso facto um compositor, um intérprete, um criador. Também a audiência é poiética, o que equivale a considerá-la intencionalmente transcendente no seu fito. De novo nas palavras do próprio Gil, interpretadas à maneira de quem o julga ter escutado: “... não se destrinçará a escuta do auditor da criação pelo compositor (...). De certa maneira, indo da forma ao sentimento, a escuta reproduz a criação em sentido inverso." ${ }^{31}$ Mas não se leia a coincidência possível entre o regresso ao eu próprio e o regresso ao princípio - da capo - como uma expressão temporal, não obstante o tempo ser a gramática própria da música. A repetição aqui em causa significa não a repetição da novidade, mas a repetição ou a convocação da atualidade ${ }^{32}$. Ou melhor dizendo: a repetição de uma escuta que

${ }^{29}$ F. GiL, "Exemplos...”, p. 16.

${ }^{30}$ F. GIL, "Exemplos..." p. 16.

${ }^{31}$ F. GiL, "Exemplos...", p. 34.

${ }^{32}$ Abordámos a questão da novidade, sob outro prisma embora, in «"Aliqua est effectibilis, ergo aliqua effectiva'. Originalidade e novidade em Filosofia» Itinerarium 55 (2009), pp. 311-327. 
conserve o que muda - e na música tudo parece mudar - ou seja, a energeia ou mesmo a entelecheia que o som é, apenas quando se mostra (zeigen) e não quando é dito (sagen) - para roubarmos dois verbos que no Tractatus de Wittgenstein dão que pensar ${ }^{33}$. Interpretando as palavras de Eichendorff e de Adorno, mas dialogando sempre com F. Gil, Mário Vieira de Carvalho também disse qualquer coisa de parecido, embora referindo-se às palavras feitas música: "Quem se exprime é a natureza, as coisas (...). As palavras ganham o estatuto de música precisamente no momento em que, deixando de veicular imagens captadas pelo sujeito, passam a representar, dir-se-ia a alma das coisas..." ${ }^{34}$ Ora, "a alma das coisas revela-se precisamente pela escuta, por aquilo que na linguagem transcende o significacional ou o intencional e alucina como música." 35

Mais do que de uma catafática da escuta - e porque não dizê-lo? de uma autêntica pleromática da escuta -, tal como lemos a proposta de F. Gil ${ }^{36}$, preconizaríamos pela nossa banda, uma nova ultrapassagem, a de qualquer oposição apofática/catafática pela proposta do que vimos chamando "audiência". Já há alguns anos havíamos dialogado com Gil a propósito da evidência ${ }^{37}$ e é chegada a altura de acrescentarmos a este diálogo - infelizmente agora impossível antes da consumação dos tempos - a dimensão correlativa e paralela da audiência. Se naquele caso ela se terçava no plano de uma filologicamente escandalosa rela-

${ }^{33}$ Cf. também F. GiL, "Exemplos...”, p. 34: "O mistério não se elucida, exibe-se e a música é por esta razão o instrumento adaptado para lhe dar forma"; cf. de maneira mais lata, MARINA R. THEMUdo, Ética e Sentido. Ensaio de reinterpretação do 'Tractatus Lógico-philosophicus' de Ludwig Wittgenstein, Coimbra 1989, pp. $281 \mathrm{sg}$.

${ }^{34}$ M.V. de Carvalho, "O engano dos significados ou a prisão da linguagem: Da poética musical de Eichendorff à poética musical de Adorno", in F. GIL \& MÁrio VieIRa de CARVAlho, A 4 mãos. Schumann, Eichendorffe outras notas, Lisboa 2005, p. 71 (os sublinhados são do autor).

${ }^{35}$ M.V. de Carvalho, "O engano...", p. 76.

${ }^{36}$ F. GIL, "Exemplos...”, p.30: "a inteligibilidade do 'inexprimível' é plena desde que saibamos escutar, isto é, esquecer que a infeção do espírito e da mente pela linguagem nos precipita a cada instante na tentação de dar nomes às coisas, mesmo àquelas que só são bem expressas se não lhes dermos um nome - e as ouvirmos."

${ }^{37}$ M.S de Carvalho, "Estudo Complementar", in Pseudo-Dionísio Areopagita. Teologia Mística, Porto, 1996, pp. 88-90. 
ção entre videre e vivere, subjacente ao que julgámos ser a metáfora da Treva no fundo de uma "e-vi(d)/(v)ê-ncia" - "a e-vidência do evidente (...) é o próprio e-vidente evidenciado" 38 - quer-nos parecer agora que só a metáfora do Inaudito, ou melhor ainda, do Inaudível, pode acolher o excesso, a soberania e a autossuficiência que a música é e concita ao ato da escuta feita energeia ou entelecheia. Para tudo dizer numa palavra: “... se a música é isso, e, portanto, a essência dela é o inaudível, então o que se escuta verdadeiramente nela é Deus. ${ }^{39}$ A heterofonia do nome próprio, portanto.

Simplesmente, para nós, e pelo próprio estatuto do inaudível, este processo iterativo de escuta audiente carece precisamente da infinita repetição que saiba assumir, afinal ou corajosamente, o princípio de que nunca se chega a ouvir o que pela sua condição sempre será no limite inaudível. Questão de teleologia, portanto, quanto de etiologia; ou questão não de disciplina, quanto de autêntica vivência na/da escuta - ou feita escuta. Para evitar quaisquer equívocos interpretativos: mais do que uma qualquer metafísica da música (nem na esteira de Schopenhauer, nem na de Heidegger), a "audiência" remete-nos simplesmente para uma atitude humana genuinamente filosófica, ou coincidente com ela, caso se prefira dizer assim, a da liberdade para ouvir o que ainda não foi ouvido. Falamos de uma complexa, melhor de uma completa implicação, o outro nome da energeia ou da entelecheia, enquanto resposta à pergunta “o que significa ouvir?" Implicação de som, de tom, de timbre, de altura, de acentuação, de duração, mas também de atenção, de disponibilidade, de abertura, de tempo, do Mundo, do Homem e de Deus.

${ }^{38}$ M.S. de Carvalho, "Estudo...", p. 89.

${ }^{39}$ M.V. DE CARVAlHo, "O engano...", p. 77 (os sublinhados são do autor) 